\title{
A new capsule endoscopy feature of serosal eosinophilic enteritis
}

A 37-year-old woman presented with intermittent, colicky abdominal pain, vomiting, and abdominal distension since the past 20 days. There was no history of fever, diarrhea, or blood or mucus in the stool. The abdomen was slightly distended but not tender, and bowel sounds were normal. Blood tests revealed eosinophilia (white blood cell [WBC] count $11.6 \times 10^{9} / \mathrm{L}$, eosinophils $3.6 \times 10^{9} / \mathrm{L}$ ) and serum albumin was $0.4 \mathrm{~g} / \mathrm{L}$. Stool cultures and a parasitological examination were negative.

No air-fluid levels were seen on abdominal radiography, and an abdominal ultrasound showed a small amount of fluid in the pouch of Douglas. Both upper and lower gastrointestinal endoscopic examinations were normal, and ileal biopsies revealed only occasional eosinophils. An abdominal computed tomography (CT) scan was unremarkable. Ascitic fluid paracentesis yielded clear yellow fluid with no malignant cells, albumin $0.29 \mathrm{~g} / \mathrm{L}, \mathrm{WBC}$ count $6.5 \times 10^{9} / \mathrm{L}$, and eosinophils $5.5 \times 10^{9} / \mathrm{L}$. Capsule endoscopy examination showed dark blue coloration of the deeper layers of the small-bowel wall from the midileum to the ileocaecal valve, with normal villi and no surface erosions ( $\bullet$ Fig. 1). Repeated colonoscopy showed normal ileal mucosa up to $30 \mathrm{~cm}$ beyond the ileocaecal valve. No blue coloration was seen ( $\bullet$ Fig. 2). Repeated biopsy specimens from the terminal ileum showed only mild/borderline mucosal eosinophil infiltration (10-20/high-power field [HPF] $\times 40$ ). Serosal eosinophilic enteritis with mucosal sparing was diagnosed, and the patient's symptoms and blood eosinophilia resolved with an oligoantigenic diet.

Symptoms of eosinophilic enteritis vary, depending on the site and extent of the eosinophilic infiltrate. Mucosal eosinophilic enteritis presents with abdominal pain, vomiting, and diarrhea. Infiltration of the muscularis propria leads to obstructive symptoms. Involvement of the serosa presents with ascites [1]. Diagnosis is based on the presence of eosinophilic infiltration in biopsy samples ( $\geq 20$ eosinophils/HPF) [2].
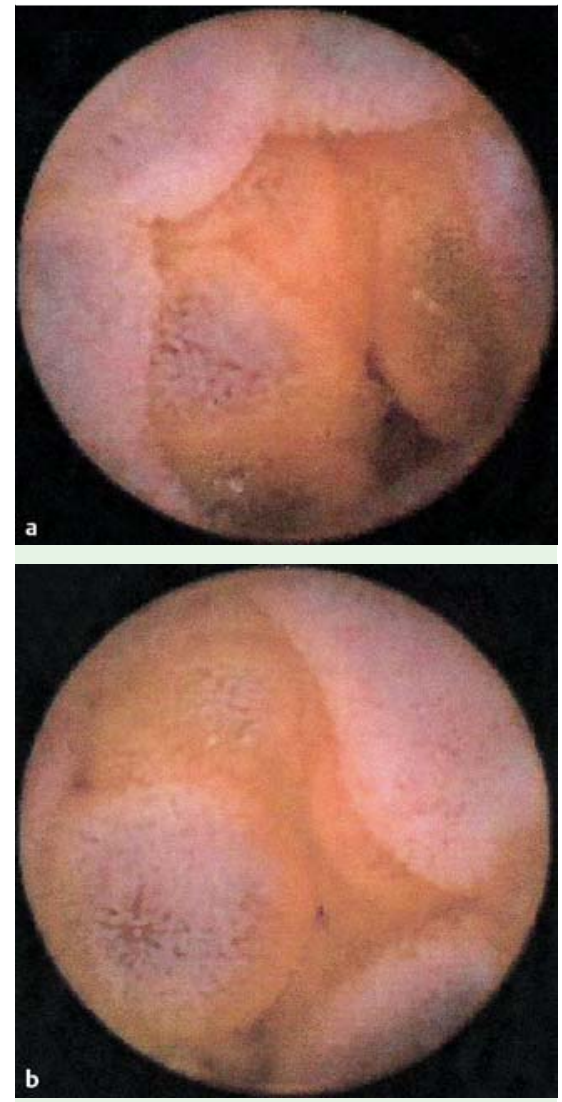

Fig. 1 a, b Capsule endoscopy showing dark blue coloration of the deeper layers of the terminal ileum with no mucosal lesions.

In the present case, capsule endoscopy revealed blue coloration of the deeper layers, without mucosal changes, indicating that the eosinophilic infiltration had spared the mucosa. The latter was confirmed on histological examination, which showed mild/borderline eosinophilic infiltration [2]. Previous capsule endoscopy reports of eosinophilic enteritis have consisted of patchy, erythematous mucosal lesions with centrally flattened villi or erosions with aphthous ulcers [3]. Our new capsule endoscopy finding indicates that blue coloration of the deep layers of the small-bowel wall with preservation of the mucosal morphology suggests a diagnosis of eosinophilic enteritis of the serosal type.

Endoscopy_UCTN_Code_CCL_1AC_2AD

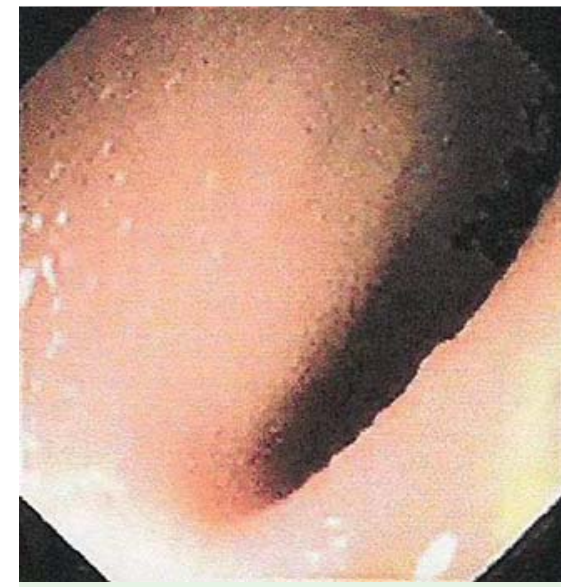

Fig. 2 lleoscopy using a colonoscope showing no blue coloration in the terminal ileum.

\section{A. Koumi, M. Z. Panos}

Department of Gastroenterology, Euroclinic of Athens, Athens, Greece

\section{References}

1 Zhou HB, Chen JM, Du Q. Eosinophilic gastroenteritis with ascites and hepatic dysfunction. World J Gastroenterol 2007; 13: $1303-1305$

2 Talley NJ, Shorter RG, Phillips SF et al. Eosinophilic gastroenteritis: a clinicopathological study of patients with disease of the mucosa, muscle layer and subserosal tissues. Gut 1990; 31: 54-58

3 Pungpapong S, Stark ME, Cangemi JR. Protein-losing enteropathy from eosinophilic enteritis diagnosed by wireless capsule endoscopy and double-balloon enteroscopy. Gastrointest Endosc 2007; 65: 917-918

\section{Bibliography}

DOI $10.1055 / \mathrm{s}-0029-1215020$

Endoscopy 2009; 41: E280

(c) Georg Thieme Verlag KG Stuttgart · New York . ISSN 0013-726X

\section{Corresponding author}

\section{Z. Panos, MD, FRCP, AGAF}

Department of Gastroenterology

Euroclinic of Athens

Athanassiadou 9

11521 Athens

Greece

mpanos@euroclinic.gr 